\title{
Educação Infantil e currículo: contribuições freirianas ao debate
}

\author{
Children's Education and curriculum: \\ Freire's contributions issue
}

\author{
Adilson De Angelo \\ Professor Adjunto - Universidade do Estado de Santa Catarina; \\ Grupo de Estudos em Educação Infantil - Gedin/FAED/UDESC; \\ Grupo de Estudos e Pesquisas na Pequena Infância - Nupein/UFSC. \\ adilsondeangelo@gmail.com
}

\begin{abstract}
Resumo
Este texto advém do debate que tem procurado problematizar as questões da Educação Infantil no sentido que ela cumpra plenamente a sua função sociopolítica e pedagógica na educação e no cuidado da criança pequena. Como mote para a discussão aqui proposta, trabalham-se algumas questões sobre currículo, compreendendo-o como um conjunto sistematizado de práticas culturais no qual se articulam diferentes experiências e saberes das crianças, de suas famílias, dos profissionais e de suas comunidades de pertencimento, assim como os que foram produzidos historicamente pela humanidade. Em primeiro lugar, o texto situa o tema no conjunto das conquistas históricas da Educação Infantil. A seguir, discute e problematiza algumas questões do currículo no campo da Educação Infantil, tomando o universo freiriano como contribuição ao debate.
\end{abstract}

Palavras-chave: Criança. Currículo. Educação Infantil. Pedagogia freiriana.

\begin{abstract}
This work results from the discussion about Early Childhood Education and curriculum according to National Curriculum Guidelines. The aim of this study has been problematized by the questions of Early Childhood Education in the sense that it achieves the socio-political and pedagogical function in the education and in the early childhood care. We take some questions about curriculum as the initial point for the proposal discussion, which is understand as a systematic set of cultural practices that articulates different experiences and knowledge of children, their families, professionals and their communities as well as the knowledge historically produced by humanity. Firstly, this text intends to present the childhood education in the context of the historical achievements. Afterwards, we discuss and some questions about curriculum in the childhood education are problematized, taking the Freirian pedagogy universe as the main contribution.
\end{abstract}

Key words: Child. Curriculum. Early Childhood Education. Freirean Pedagogy. 


\section{Pretextos}

Sem sombras de dúvidas, a Constituição Federal de 1988 marca o reconhecimento da Educação Infantil como dever do Estado e solidifica o atendimento em creches e pré-escolas como direito social das crianças. Nossas memórias nos informam que, na aquarela dessas conquistas, podemos identificar diferentes nuances e matizes marcadas pela grande participação dos movimentos sociais populares, reunindo mulheres, trabalhadores (as), militantes políticos (as) e, sobretudo, profissionais da educação. Ao longo da história, tais movimentos surgiram para atuar em torno de problemas estruturais e conjunturais que precisavam ser superados ou amainados. Nesses casos, a dificuldade de acesso da criança brasileira a uma Educação Infantil que a reconhecesse e respeitasse como sujeito de direitos configurou-se como problema a ser superado pela mobilização popular. (DE ANGELO, 2010)

Assim, nos últimos tempos, pensar a Educação Infantil no contexto brasileiro significa, necessariamente, dialogar com as questões suscitadas nos seguintes documentos: a Constituição Federal (1988), o Estatuto da Criança e do Adolescente (1990), a Lei de Diretrizes e Bases da Educação Nacional (1996) e as Diretrizes Curriculares Nacionais para a Educação Infantil (1999/2009). Somam-se a esse diálogo as discussões mais ampliadas sobre os direitos das crianças, a eficácia dos serviços a elas destinados e a intensidade dos estudos e debates que nos informam das experiências que se vão desenhando nos espaços coletivos de educação/cuidado destinados à criança pequena. Desde então, o campo da Educação Infantil tem mobilizado diferentes atores no processo de elucidação das concepções de infância, criança, educação e cuidado, assim como das formas em que se darão as práticas pedagógicas de aprendizagem e desenvolvimento infantil.

A publicação de uma coletânea de textos organizados por Ana Lúcia Goulart de Faria e Marina Silveira Palhares - "Educação Infantil pós-LDB: rumos e desafios" (1ª edição de 1999) - já chamavam a nossa atenção, naquela altura, para a necessidade de "documentar uma importante polêmica dos nossos tempos: currículo e Educação Infantil” (FARIA; PALHARES, 1999, p. 1). Os textos desta coletânea trazem e fomentam, direta ou indiretamente, discussões importantes sobre questões de currículo, formação de professores, gestão, participação das famílias e da comunidade, critérios de qualidade, avaliação de resultados, material didático, legislação, entre outros temas que envolvem essencialmente a 
Educação Infantil. Pretenderam suas organizadoras que as reflexões daí advindas pudessem contribuir de "forma mais contundente, na formulação de políticas e práticas de Educação Infantil que respeitem os direitos das crianças" (op.cit., p.4).

Passados alguns anos, as questões problematizadas por esse grupo de autores ainda se apresentam bastante atuais. Por isso, continuamos atentos para que os nossos otimismos e utopias em relação à educação das crianças pequenas, sobretudo à sua educação em espaços coletivos, estejam presentes nas mais diferentes instâncias e agendas. A consolidação das Diretrizes Curriculares Nacionais para a Educação Infantil (DCNsEI), fixada na sua primeira versão em 1999 e na sua revisão e atualização em 2009, foi importante no sentido de reunir as conquistas no campo da política, da produção científica e da vigilância dos movimentos sociais.

As Diretrizes Curriculares Nacionais para a Educação Infantil, de caráter mandatório, orientam a formulação de políticas, incluindo a de formação de professores e demais profissionais da Educação, e também o planejamento, desenvolvimento e avaliação pelas unidades de seu Projeto Político-Pedagógico e servem para informar as famílias das crianças matriculadas na Educação Infantil sobre as perspectivas de trabalho pedagógico que podem ocorrer. (BRASIL, 2009, p. 3)

Confirmando algumas questões já asseguradas em documentos anteriores, as DCNsEI propõem o entendimento da Educação Infantil como a primeira etapa da Educação Básica, oferecida espaços institucionais não domésticos de creches e pré-escolas, que se configuram como estabelecimentos educacionais, públicos ou privados, que educam e cuidam de crianças de zero a cinco anos de idade no período diurno, em jornada integral ou parcial, regulados e supervisionados por órgão competente do sistema de ensino e submetidos a controle social. É dever do Estado garantir a oferta de Educação Infantil pública, gratuita e de qualidade, sem requisito de seleção.

A criança, assim, é vista na sua condição de sujeito histórico e de direitos que, nas interações, relações e práticas cotidianas que vivencia, se constrói e é construída em sua identidade pessoal e coletiva. Sendo produzida na e sendo produtora de cultura, à criança se confere, portanto, a condição de sujeito dotado de ou percebido em sua concretude histórica. 
É em torno deste movimento que temos observado o esforço de se pensar, no âmbito das diferentes redes municipais, as orientações educativas para a criança de zero a cinco anos que tomem por fundamentos básicos:

i) Princípios éticos: valorização da autonomia, da responsabilidade, da solidariedade e do respeito ao bem comum, ao meio ambiente e às diferentes culturas, identidades e singularidades;

ii) Princípios políticos: dos direitos de cidadania, do exercício da criticidade e do respeito à ordem democrática;

iii) Princípios estéticos: valorização da sensibilidade, da criatividade, da ludicidade e da diversidade de manifestações artísticas e culturais. (BRASIL, 2009, p. 8-9)

Ter em atenção esses princípios básicos, conforme determinam as DCNsEI, pressupõe alguns movimentos de ruptura com políticas e práticas pedagógicas que historicamente tomaram a criança como objeto de tutela, que precisa ser conduzida, governada, ajuizada, vigiada pelos adultos, estes, sim, os únicos detentores dos saberes, com poder de governar os tempos e de determinar as possibilidades de ser criança. Romper com essas concepções e práticas pressupõe adotar como princípio educativo, nas creches e pré-escolas, a construção de outros olhares e de outras escutas em relação às crianças. Significa tomá-las "como ator ativo e criativo, como um sujeito e cidadão de potenciais, direitos e responsabilidades, com sua própria inclinação e poder para aprender, investigar e se desenvolver como ser humano em uma relação ativa com outras pessoas" (MOSS, 2002, p. 243). Uma criança que pode ser parte ativa no processo de criação de conhecimento, que em interação com o mundo ao redor é também ativa na construção, na criação de si mesma, de sua personalidade e de seus talentos; uma criança que se constitui protagonista "sobre o seu próprio processo de aprendizagem e tendo o direito de interpretar o mundo". (Id.ib.)

\section{Currículo e Educação Infantil: o debate continua}

Como poderíamos, então, pensar a questão do currículo na Educação Infantil levando em conta todas as questões anteriormente apresentadas? Que 
sentido se tem conferido a esse termo nos saberes e fazeres da Educação Infantil no contexto em que nos encontramos? Aqui, somos desafiados a assumir o que orientam as DCNsEI:

Art. $3^{\circ} \mathrm{O}$ currículo da Educação Infantil é concebido como um conjunto de práticas que buscam articular as experiências e os saberes das crianças com os conhecimentos que fazem parte do patrimônio cultural, artístico, ambiental, científico e tecnológico, de modo a promover o desenvolvimento integral de crianças de $0 \mathrm{a}$ 5 anos de idade. (BRASIL, 2009, p. 19)

Essas práticas se efetivam nas relações sociais que as crianças estabelecem com os seus pares e também com os adultos, e que integram a construção de suas identidades. Daí decorre a exigência de que as vivências que se efetivam no cotidiano da Educação Infantil sejam conferidas de intencionalidade pedagógica, responsavelmente planejadas e frequentemente avaliadas. Um currículo que atenda à integralidade e indivisibilidade das dimensões expressivo-motora, afetiva, cognitiva, linguística, ética, estética e sociocultural das crianças, e que as assuma como centro do planejamento curricular, como sujeito histórico e de direitos que problematiza e constrói sentidos sobre a natureza e a sociedade, nesse passo produzindo cultura. Um currículo, portanto, que tenha como eixos norteadores as interações e as brincadeiras, que reconheça a centralidade da linguagem no processo da criança dizer-se e dizer o mundo.

Nas suas experiências de aprendizagem, as crianças precisam ser reconhecidas e desafiadas em suas possibilidades criativas. É necessário que se tenha sempre em conta que há todo um mundo que se descortina e se apresenta a elas repleto de perguntas. Nas suas especificidades e interesses singulares, em busca de respostas, elaboram hipóteses e sentidos pessoais sobre si mesmas, sobre as coisas e sobre o mundo. Decorre daqui a necessidade de se pensar um desenho de currículo que seja capaz de problematizar os conceitos que emergem dos saberes oriundos das práticas e vivências das crianças, ao mesmo tempo em que considera a emergência de novos conceitos que garantam a apropriação ou a construção de outros conhecimentos. Implica um planejamento curricular que se preocupe com o interesse e a curiosidade pelo conhecimento do mundo, na familiaridade de diferentes linguagens, na interação com o outro, na relação com a natureza. 
Pensar na problematização ou na elaboração de conceitos em Educação Infantil não significa defender um currículo pautado no mero ensino de conteúdos, na perspectiva da escolarização. Aliás, somos contundentemente informados pelas DCNsEI (art. 11) da necessidade de rompimento com essa perspectiva de "antecipação de conteúdos que serão trabalhados no Ensino Fundamental" (BRASIL, 2009, p. 12). Trata-se de pensar "como orientar o trabalho junto às crianças de até três anos em creches e como garantir práticas junto às crianças de quatro e cinco anos que se articulem, mas não antecipem processos do Ensino Fundamental" (BRASIL, 2009, p. 2).

É um ganho histórico o reconhecimento da Educação Infantil como primeira etapa da Educação Básica, mas

seria um equivoco engessá-la nos moldes do ensino fundamental, que lhe sucede, em uma perspectiva preparatória, propedêutica. Se a criança vem ao mundo e se desenvolve em interação com a realidade social, cultural e natural, é possível pensar uma proposta educacional que lhe permita conhecer esse mundo, a partir do profundo respeito por ela. Ainda não é o momento de sistematizar o mundo para apresentá-lo à criança: trata-se de vivê-lo, de proporcionar-lhe experiências ricas e diversificadas. (KUHLMANN JR, 2003, p. 57)

Dessa reflexão decorre a necessidade de se propor, no âmbito das redes municipais, um posicionamento político e pedagógico acerca do currículo para a Educação Infantil que possa provocar um cotidiano de situações agradáveis, estimulantes, que desafiem as crianças (na interação entre elas, com os adultos e com o mundo) a se expressar e a se comunicar nas diferentes linguagens, à criação e organização de pensamentos e ideias, ao desejo de conviver, brincar e trabalhar em grupo, à possibilidade de mediar e resolver problemas e conflitos, ao acesso e à apropriação dos saberes historicamente construídos pela humanidade e que circulam em nossa sociedade. Um currículo que consiga articular as interações, as brincadeiras e as diferentes linguagens; que nos permita e nos desafie a pensar e a propor os tempos e os espaços da/na Educação Infantil como espaços-tempos de ser criança e de se viver a infância como tempo de direitos; que 
nos leve a pensar o processo educativo- pedagógico para e com as crianças como processo de formação humana para a participação social e para a cidadania.

\section{Contribuições freirianas ao debate}

Ao olharmos para esses desafios curriculares construídos e assumidos no campo da Educação Infantil, podemos perceber que eles encontram eco nas inquietações freirianas de se pensar o papel e o lugar da educação na construção da humanidade do sujeito humano, considerando a sua vocação ontológica de ser mais. Como afirmamos em outras ocasiões (DE ANGELO, 2006; 2008), o pensamento de Paulo Freire traz fecunda contribuição para a emergência e consolidação de diferentes propostas de educação, desafiando a sua própria (re) invenção nas mais diversas experiências pedagógicas desenvolvidas em conjunto com crianças, jovens, adolescentes, adultos, homens e mulheres em diferentes partes do mundo. A confiança na possibilidade de uma cidadania planetária que as suas ideias apresentam tem sido assumida como ponto de partida para diferentes práticas educativas, escolares e não escolares.

Assumimos que as ideias apresentadas por Freire sustentam a afirmação de que a Educação Infantil, como espaço permanente de busca do ser mais, também pode ser compreendida como um momento da experiência dialética de humanização dos seres humanos que se dá na relação dialógica entre educadores e educandos. Como as próprias DCNsEI explicitam, a constituição desse espaço-tempo como um espaço-tempo infantil não afasta a possibilidade do desenvolvimento de um trabalho que se comprometa com o cultivo dos valores da solidariedade, da amizade, da sensibilidade, do respeito às diferenças, do senso crítico, do aprendizado dos direitos e dos deveres. Pois, parafraseando Paulo Freire, não importará com que faixa etária trabalhe o educador ou a educadora, a educação é sempre um processo a ser realizado com gente - pequena, crescida, homem, mulher, mas gente em permanente processo de busca. Gente em processo de formação, de mudança, de re-invenção, capaz de sentir, de amar e de querer saber. Por tudo isso, gente que pode ser sujeito da sua própria humanização.

Partindo da hipótese de que a Educação Infantil pode se constituir como o espaço/tempo de trabalho com as crianças, tendo delas uma visão de sujeitos de direito, de desejo e de conhecimento, parece-nos possível falar 
de uma Educação Infantil cuja prática esteja fundada nos princípios de uma educação na e para a cidadania, com vistas à emancipação dos educandos; como processo que pode contribuir para a construção da humanidade do ser humano, que toma como objeto de preocupação "os processos de constituição do conhecimento pelas crianças, como seres humanos concretos e reais, pertencentes a diferentes contextos sociais e culturais, também constitutivos de suas infâncias". (ROCHA, 2010)

Para Freire, na educação, "se seu compromisso é o da libertação, o seu quefazer, ação e reflexão, não pode dar-se sem a ação e a reflexão dos outros" (FREIRE, 1987, p. 70). Por isso, a educação como quefazer humano, que ocorre num espaço e num tempo de interação entre os sujeitos-mundo ${ }^{1}$, se pode afirmar como processo que, esforçando-se no sentido da desocultação da realidade, contribui para que o ser humano existencialize a sua real vocação: transformar-se a si próprio, transformando a realidade. É, portanto nesta

inconclusão do ser, que se sabe como tal, que se funda a educação como processo permanente. Mulheres e homens se tornaram educáveis na medida em que se reconheceram inacabados. Não foi a educação que fez mulheres e homens educáveis, mas a consciência da sua inconclusão é que gerou a sua educabilidade. É também na inconclusão de que nos tornamos conscientes e que nos inserta no movimento permanente de procura que se alicerça a esperança. (FREIRE, 2002, p. 64)

Os horizontes pedagógicos, que aqui assumimos como um posicionamento político-ideológico e epistemológico, é que nos impulsionam a afirmar as possibilidades de contribuição do pensamento de Paulo Freire e da ação freiriana para a consolidação de uma proposta pedagógica para a Educação Infantil que redimensione as finalidades dos processos educativos voltados às crianças pequenas. Nessa direção, confirma-se uma dimensão curricular que tenha como desafio garantir à criança o acesso a processos de apropriação, renovação e articulação de conhecimentos e aprendizagens de diferentes linguagens, assim como o direito à proteção, à saúde, à liberdade, à confiança, ao respeito, à dignidade, à brincadeira, à convivência e à interação com outras crianças. 
A possibilidade de conferir à Educação Infantil essa dimensão problematizadora, que muito se aproxima do universo freiriano, pode significar afastamento do mero assistencialismo que, geralmente, serve à dominação, inibe a criatividade, tolhe a intencionalidade da consciência e nega aos educandos a sua vocação ontológica e histórica de ser mais. Contrariamente, uma educação libertadora pode proporcionar um trabalho educativo com crianças pequenas fundamentado na criatividade que, estimulando a reflexão e a ação verdadeira dos educandos e educandas sobre suas próprias realidades, poderá ajudá-los a responder "à sua vocação como seres que não podem autenticar-se fora da busca e da transformação criadora" (FREIRE, 1987, p. 41). Nos termos das DCNsEI, é imperativo

considerar que a criança, centro do planejamento curricular, é sujeito histórico e de direitos que, nas interações, relações e práticas cotidianas que vivencia, constrói sua identidade pessoal e coletiva, brinca, imagina, fantasia, deseja, aprende, observa, experimenta, narra, questiona e constrói sentidos sobre a natureza e a sociedade, produzindo cultura. (BRASIL, 2009, p. 19)

Essa possibilidade, como também orienta Freire, acaba por exigir uma nova postura do educador, a quem não será permitido negar a sua contribuição para que as crianças - sujeitos-educandos - se constituam, cada vez mais, como protagonistas de direito, de desejo e de conhecimento; sem esquecer que o trabalho com crianças exige atenção "à difícil passagem ou caminhada da heteronomia para a autonomia (...) [e que a sua presença] tanto pode ser auxiliadora como perturbadora da busca inquieta dos educandos" (FREIRE, 2002, p. 78 - grifos nossos). Porque, acrescenta ele, a educação será sempre um processo realizado por gente, seja ela adulto, jovem ou criança... gente em processo permanente de busca.

Resulta dai a importância de que sejam dadas condições para a constante reflexão sobre a prática docente cotidiana, em termos pedagógicos, éticos e políticos, e para a tomada de decisões sobre as melhores formas de mediar a aprendizagem e o desenvolvimento infantil, considerando o coletivo de crianças e suas singularidades. Assim, nos processos de formação inicial e continuada dos profissionais que atuam para/com a criança pequena, há de se descartar, 
desde logo qualquer consequência identificada com uma isenção da atuação docente, da sistematização e da organização da ação pedagógica e, é óbvio, com qualquer limite ao rigor da formação dos professores para atuar na educação infantil. Ao contrário, amplia-se a função docente e as exigências formativas, quando a ação pedagógica extrapola uma perspectiva simplesmente reprodutora e transmissiva. (ROCHA, 2010, p. 16)

Por outro lado, a crítica ao que temos definido como antecipação da escolarização também não se identifica, como vimos até aqui, com qualquer negação da função de formação intelectual das crianças e de apropriação cognitiva de outros saberes. As práticas pedagógicas devem ocorrer de modo a não fragmentar a criança nas possibilidades "de viver experiências, na sua compreensão do mundo feita pela totalidade de seus sentidos, no conhecimento que constrói na relação intrínseca entre razão e emoção, expressão corporal e verbal, experimentação prática e elaboração conceitual"' (BRASIL, 2009, p. 9). Nas brincadeiras e nas interações, articuladas pelas diferentes linguagens, vivendo a sua dimensão de incompletude, as crianças vão protagonizando diferentes situações em que buscam articular suas experiências e saberes com os conhecimentos que fazem parte do patrimônio cultural, artístico, ambiental, científico e tecnológico. Trata-se de promover o desenvolvimento integral da criança no mundo, com o mundo.

A experimentação e, consequentemente, a vivência da Educação Infantil como realidade que pode contribuir com a desocultação de verdades tornam-se imperativas para o exercício da intervenção crítica e criativa das crianças sobre o mundo, transformando-o sempre que possível. Isto acaba por requerer e ser a resultante de um novo ângulo de visão sobre o conceito de infância que permita emergir uma imagem de criança vista em suas condições concretas de existência, social, cultural e historicamente determinada (KRAMER, 1998). Isto é, a criança entendida como sujeito historicamente construído, mas não concluído. Por isso mesmo, um sujeito em processo permanente de busca do ser mais que, estando consciente da sua inconclusão, pode vir a ser protagonista da sua humanização, tornando-se cada vez mais gente. 


\section{Na continuidade da conversa ou... para seguir o diálogo}

A pedagogia de Paulo Freire articula-se ao universo da Educação Infantil por propor um entendimento do sujeito humano nos seus desejos de liberdade, de autonomia, de querer saber, de poder esperançar, na confluência com sua historicidade, com sua produção cultural e com sua sociabilidade. Ela procura ser a manifestação de que a inexorabilidade do futuro é a negação da própria História. E por isso mesmo é também anunciadora da humanidade do ser humano, como processo que abarca as ações, os pensamentos, os desejos do sujeito humano, adulto ou criança, mulher ou homem. É assim que a sua proposta educativa é anunciadora do sujeito plural, constituído de sujeitos capazes de projetar novas relações sociais necessárias à construção da humanidade do ser humano. Estas as razões de sua pertinência nos mais diferentes contextos, sobretudo naqueles em que imperam mecanismos de subordinação, exclusão, negação da vocação de ser mais. No trabalho com crianças pequenas, ela vem sugerir a composição de um espaço-tempo educativo no qual a criança seja constituída e constituinte de sua subjetividade e de seus conhecimentos, na afirmação de um ambiente de autonomia e cooperação.

"Quanto mais cultural é o ser, maior a sua infância, sua dependência de cuidados especiais" (FREIRE, 2002, p. 56). Para o patrono da educação brasileira, a ideia de infância pode ser assumida como um tempo contrário àquele que coíbe o sujeito humano na sua singularidade, negando a sua implicação na abertura ao novo, ao conhecimento a ser construído, repartido, reinventado. Bem ao contrário, com Paulo Freire é possível afirmar a infância como um espaço e um tempo biológico e cultural, propício à experimentação, à curiosidade indagadora, à busca de uma consciência que o inscreva no movimento permanente de alicerçar a esperança. Ousando ainda mais, podemos dizer que a infância confirma o pensamento de Freire de que o ser humano está "programado", mas para aprender.

Em suma, as contribuições do pensador pernambucano são extremamente importantes no processo de compreensão do currículo da Educação Infantil como conjunto de práticas que articulam as experiências e os saberes das crianças com os conhecimentos que fazem parte do patrimônio cultural, artístico, ambiental, científico e tecnológico, de modo a promover o desenvolvimento integral da criança pequena. Freirianamente falando, a Educação Infantil pode (e deve!) ser 
um espaço-tempo capaz de garantir à criança a vivência de apropriação, renovação e articulação de conhecimentos e aprendizagens de diferentes linguagens, assim como o direito à proteção, à saúde, à liberdade, à confiança, ao respeito, à dignidade, à brincadeira, à convivência e à interação com outras crianças. $\mathrm{O}$ direito de, sendo criança, ser gente mais gente.

\section{Nota}

1 Em seus escritos iniciais, Freire utiliza a expressão "homem-mundo" para dizer da necessidade de se "perceber corretamente as relações consciência-mundo ou homemmundo" (FREIRE, 1981, p. 81). Atendendo ao desafio do próprio Paulo Freire de "recusa à ideologia machista, que implica necessariamente a recriação da linguagem (pois) mudar a linguagem faz parte do processo de mudar o mundo" (FREIRE, 2001, p. 68), este termo tem sido assim grafado quando, na perspectiva freiriana, a relação sujeito-mundo é problematizada.

\section{Referências}

DE ANGELO, Adilson. A pedagogia de Paulo Freire nos quatro cantos da educação da infância. In: I CONGRESSO INTERNACIONAL DE PEDAGOGIA SOCIAL, 2006. Proceedings online. Faculdade de Educação, Universidade de São Paulo, Available from: < http://www. proceedings.scielo.br/scielo.php?script=sci_arttext\&pid=MSC0000000092006000100001\&1 ng=en\&nrm=abn $>$. Acess on: 2 Dec. 2012.

, Adilson. Os meninos e as meninas fizeram um belo balão: contribuições do pensamento de Paulo Freire para uma leitura do mundo da Educação de Infância. Coleção Teses e Dissertações. Recife: Edições Bagaço, 2008.

, Adilson. A Educação Infantil no contexto dos Movimentos Sociais: duas leituras possíveis. Especiarias - Caderno de Ciências Humanas, Dossiê: Educação, políticas públicas e mudanças sociais. Vol. 12 e 13, nº 22 e 23, janeiro/junho 2010, p. 123-153.

BRASIL. Ministério da Educação e Cultura. Secretaria de Educação Básica. Diretrizes curriculares nacionais para a Educação Infantil; Resolução CNE/CEB 5/2009. Diário Oficial da União, Brasília, 18 de dezembro de 2009, Seção 1.

FARIA, Ana Lúcia Goulart de; PALHARES, Marina Silveira (orgs.). Educação Infantil pós-LDB: rumos e desafios. Campinas: Autores Associados, FE-UNICAMP; São Carlos: Editora da UFSCar; Florianópolis: Editora da UFSC, 1999, 112p. (Coleção Polêmicas do Nosso Tempo, 62). 
FREIRE, Paulo. Pedagogia da Autonomia (24a edição). São Paulo: Paz e Terra, 2002. Pedagogia da Esperança: Um reencontro com a Pedagogia do Oprimido ( $8^{\mathrm{a}}$ edição). Rio de Janeiro: Paz e Terra, 2001. Pedagogia do Oprimido (17 edição). Rio de Janeiro: Paz e Terra, 1987. . Ação cultural para a liberdade (5 ${ }^{\text {a }}$ edição). Rio de Janeiro, Paz e Terra, 1981.

KRAMER, Sônia. Pesquisando infância e Educação, in KRAMER, Sônia \& LEITE, Maria Isabel (orgs.) Infância: Fios e desafios da Pesquisa. São Paulo: Papirus, 13 - 38.

KUHLMANN Jr., Moysés. Educação Infantil e Currículo. In: FARIA, Ana Lúcia e PALHARES, Marina (orgs). Educação Infantil pós-LDB. 4. ed. Campinas: Autores Associados, 2003. p. 51-65.

MOSS, Peter. Recontextualizando a Infância: crianças, instituições e profissionais. In MACHADO, Maria Lúcia (org.) Encontros e desencontros na Educação Infantil. São Paulo: Cortez Editora, 2002.

PARECER CNE/CEB nº 20/2009. Revisão das Diretrizes Curriculares Nacionais para a Educação Infantil, aprovado em 11 de novembro de 2009.

ROCHA, Eloisa Acires Candal. A Pedagogia e a educação infantil. Revista IBERO AMERICANA de Educação, no 22, 61-74, 2000.

ROCHA, Eloisa. Diretrizes Educacionais - Pedagógicas para a Educação Infantil. Prefeitura Municipal de Florianópolis. Secretaria Municipal de Educação. Florianópolis: Prelo Gráfica \& Editora Ltda., 2010.

recebido em 21 out. 2012 / aprovado em 12 nov. 2012

Para referenciar este texto:

DE ANGELO, A. Educação Infantil e currículo: contribuições freirianas ao debate.

Dialogia, São Paulo, n. 16, p. 113-125, 2012. 
